\title{
The influence of different barometric pressure conditions on bond strength of glass fiber post cemented with resin cement
}

\author{
Mohd Najib Md Razi ${ }^{1}$, Ting Khee $\mathrm{Ho}^{2^{*}}$, Natasya Ahmad Tarib ${ }^{2}$ \\ ${ }^{1}$ Postgraduate Student DclinDent (Restorative) Faculty of Dentistry, Universiti Kebangsaan \\ Malaysia, Jalan Raja Muda Abdul Aziz, 50300 Kuala Lumpur, Malaysia \\ ${ }^{2}$ Clinical Specialist (Prosthodontic), Department of Prosthodontic, Faculty of Dentistry, \\ Universiti Kebangsaan Malaysia, Jalan Raja Muda Abdul Aziz, 50300 Kuala Lumpur, Malaysia \\ *Email: tingkhee.ho@ukm.edu.my
}

\begin{abstract}
The objective of this study is to evaluate the bond strength of glass fiber post after cemented with RelyX ${ }^{\mathrm{TM}}$ Unicem resin cement under different barometric pressure conditions. A total of 20 extracted, single-rooted lower premolars were endodontically treated. Post space was prepared and the glass fiber post was cemented with RelyX ${ }^{\mathrm{TM}}$ Unicem resin cement. They were then randomly divided into two subgroups $(n=10)$ which were normal atmospheric pressure condition and hyperbaric pressure condition (higher than normal atmospheric pressure). The pullout bond strength of glass fiber post was tested using a universal testing machine. Independent t-test was used in the analysis. The mean pull-out bond strength of RelyX ${ }^{\mathrm{TM}}$ Unicem resin cement in hyperbaric pressure condition, $245.8( \pm 46.3) \mathrm{N}$ exhibited significant higher $(\mathrm{p}>0.05)$ than when compared to normal atmospheric pressure condition, $148.5( \pm 35.0)$. The bond strength of glass fiber post was influenced by different barometric pressure conditions. RelyX ${ }^{\mathrm{TM}}$ Unicem resin cement had a higher bond strength under hyperbaric pressure condition than normal atmospheric pressure condition.
\end{abstract}

Keywords: barometric pressure, hyperbaric, resin cement, bond strength, glass fiber post

\section{Introduction}

Barometric pressure or normal atmospheric pressure changes are always experienced by those who are involved in diving or flying activities. A diver for instance, during a dive descent into the first ten metres, the barometric pressure will double from 1 bar atmosphere at the surface to 2 bar atmosphere at 10 metres[1]. They will be particularly subjected to a greater pressure when they reach greater depths under the water. Diving environment creates change in barometric pressure which can initiate oral pain (dental or non-dental pain) that is called barodontalgia [2]. Apart from the barodontalgia experience, other dental implications such as fractured dental restorations, and reduce indirect restorations' retention has been reported as a result from changes in barometric pressure related to diving activities [3]. A recent study conducted by Ranna et al. reported that a high proportion of recreational divers experienced dental symptoms related to diving and suggested that dental decay and damaged restorations were to be addressed before dive 
activities [4]. Dental complications that involve compromised teeth such as endodontically treated teeth may arise due to exposure to such activities.

Endodontically treated teeth are often considered weaker than vital teeth due to the reduction of the coronal portion as a consequence of trauma or extensive loss of tooth structure [5]. To ensure and increase an adequate retention of a core foundation, the post placement must always be required for endodontically treated teeth, which has significant loss of coronal tooth structure and has become one of the preferred choice among dental practitioners [6]. The similar modulus elasticity of glass fiber post and root dentine promotes favorable stress distribution [7] and reduces the complication of vertical root fracture beneath the bone level [8].

The most common luting agents used for cementing post are zinc phosphate, resin, glass ionomer, and resin reinforced glass ionomer cements [9]. Pereira et al had found in their recent in vitro study that the bond strength values which was produced by resin cements were two times higher than resin-modified glass ionomers (RMGICs) [10]. Other research by Bitter et al also reported that, RelyXTM Unicem which was resin cement used in their study had good mechanical interaction with the root dentin through the formation of resin tags that provided micromechanical interlocking between resin and the demineralised root dentine [11]. Besides that, resin cement also appears to have low shrinkage because of their viscoelastic properties that leads to better intimate contact of the resin cement with the root canal dentine [12].

Although, there is a study done by Gulve et al [13] to evaluate the effect of pressure variations toward bond strength of glass fiber post cemented with different cements by using pressure pot to simulated diving condition, but to date, there is yet to be a study on the influence of resin cements on the bond strength of glass fiber post using a hyperbaric chamber to simulate hyperbaric condition representing a diving environment. Lyon et al in 1997 studied the effect of cycling environmental pressure changes (up to $3 \mathrm{~atm}$ ) on the retention of crowns to extracted teeth [13]. The crowns that were cemented with either zinc phosphate cement or glass-ionomer cement had significant reduced retention in approximately $90 \%$ and $50 \%$ of cases, respectively. Whereas crowns that were cemented with resin cement did not have reduced retention after pressure cycling. However, these experimental studies were only done on full metal crowns. This experimental study aims to evaluate and compare the bond strength of glass fiber post cemented with RelyXTM Unicem resin cement after being exposed to normal atmospheric pressure and hyperbaric pressure conditions.

\section{Materials and Methods}

This is an in-vitro study using 20 roots of extracted human lower premolars which were endodontically treated and restored with glass fiber posts. Ethical approval was obtained from the Research Ethical Committee, The National University of Malaysia (reference no. UKM 1.5.3.5/244/JEP-2016-104). Freshly extracted straight single-rooted with single canal teeth were used in this study. Each tooth was placed in a $5.25 \%$ sodium hypochlorite $(\mathrm{NaOCl})$ solution for 2 hours for surface disinfection and followed by ultrasonic scaling to remove soft tissue and calculus. Then the extracted teeth were stored in distilled water. Teeth with previous root 
caries, cracks, curved canals, endodontic treatment, internal resorption or calcification were excluded. The specimens were divided into two test groups of different barometric pressures which were normal atmosphere pressure and hyperbaric pressure.

\subsection{Preparation of specimens}

The crowns were decoronated along the cementoenamel junction using a high-speed diamond saw under water cooling. The length from the tip of the root to coronal surface was standardized to $15.0 \mathrm{~mm}$. Root canals were prepared $1.0 \mathrm{~mm}$ short from the apex using ProTaper ${ }^{\circledR}$ Universal Hand Files (Dentsply Maillefer, Ballaigues, Switzerland) to standardised a working length of $14.0 \mathrm{~mm}$. Irrigation was carried out with $2.0 \mathrm{~mL}$ of $2.5 \%$ sodium hypochlorite solution. Final irrigation was done with $2.0 \mathrm{~mL}$ of $17 \%$ EDTA solution and followed by rinsing with normal saline.

\subsection{Glass fiber post cementation}

After one week of storage in $100 \%$ humidity at $37^{\circ} \mathrm{C}$ to allow the sealer to set, post space was prepared on a standardize length of $10 \mathrm{~mm}$ and $4 \mathrm{~mm}$ gutta-percha (GP) was left apically. The post space was prepared with drill size no.1, followed by drill size no.2 (RelyXTM Fiber Post). After post space preparation, the canals were flushed with $2 \mathrm{~mL}$ of $2.5 \%$ sodium hypochlorite $(\mathrm{NaOCl})$ and $2 \mathrm{~mL}$ of saline solution. Each root was embedded into a plastic container (size: $52 \mathrm{~mm} \times 15 \mathrm{~mm} \times 15$ $\mathrm{mm}$ ) filled with cold cured acrylic resin (Vertex; Vertex -Dental B.V, Soesterberg, Netherlands) using the following steps: Firstly, micro retention was carried out with diamond burs at the apical third of each root, perpendicular to its long axis, promoting retention during the pull out test. Then, a glass fiber post drill \#2 was placed inside the prepared root canal and then attached to an adapted surveyor, where the long axes of the glass fiber post drill, specimen and cylinder were parallel to each other and perpendicular to the ground (Figure 1); Finally, the acrylic resin was prepared and poured inside the plastic container. Once the acrylic has set, it was removed from the plastic container and dried with compressed air and bench dried for 2 hours.

The samples then were divided into two groups of 10 samples each. After that, glass fiber post (RelyXTM Fiber Post, 3M ESPE) which is equivalent to drill size \# 2 cemented with RelyXTM Unicem resin cement into prepared root canal. Then, the specimens were stored at $37^{\circ} \mathrm{C}$ on the wet gauze for 24 hours.

\subsection{Exposure to different barometric pressure}

For each group of cement, 10 experimental specimens were kept at normal atmospheric pressure at ground level which was equal to 1 atmosphere (atm). For exposure to higher atmospheric (hyperbaric) pressure condition, 10 experimental specimens were subjected to 15 compression cycles over a range of 0 to maximum 6 atm (0-5 bar) to simulate a diving environment using a hyperbaric chamber (Hyperbaric Health: Keysborough, Victoria, Australia). In each cycle, the chamber was pressurized at the rate 10 minutes/cycle which was recommended in the manufacturer's guideline (Figure 2). 


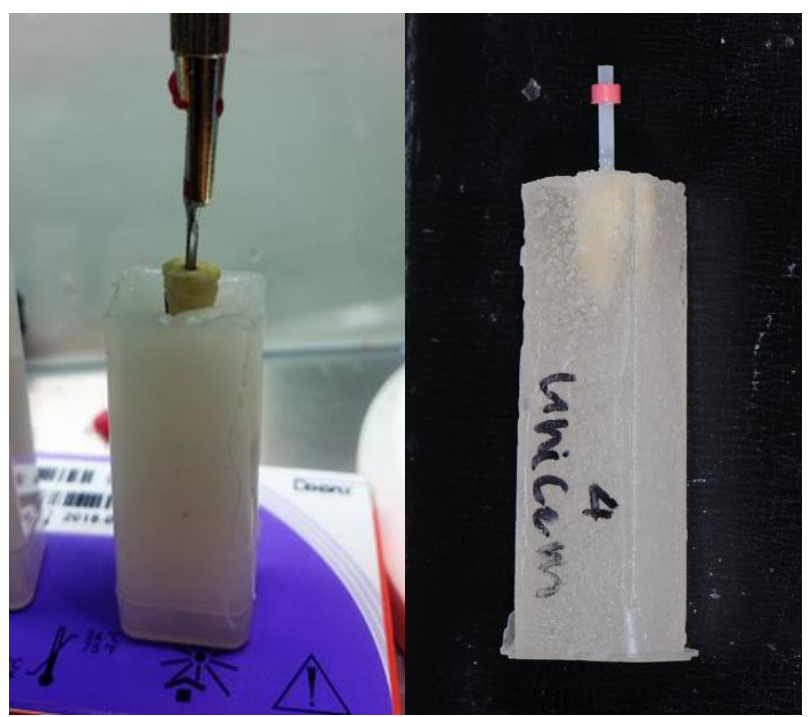

(A)

(B)

Fig 1. Preparation of samples. A; root was mounted to acrylic resin using surveyer, B; sample in acrylic resin block

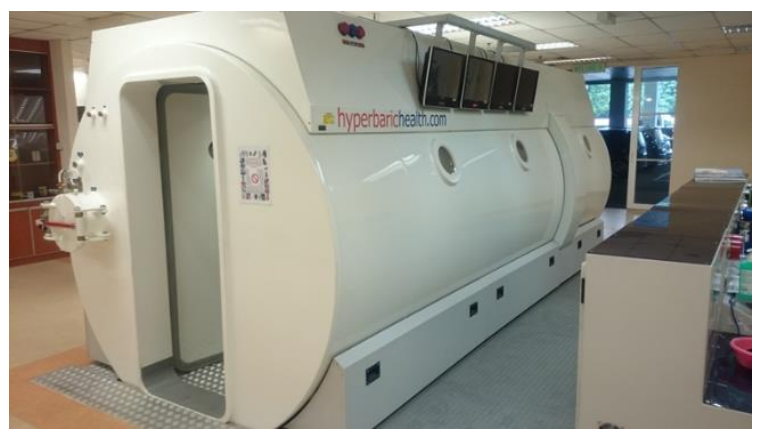

Fig 2. Hyperbaric chamber (Hyperbaric Health: Keysborough, Victoria, Australia).

\subsection{Pull out test}

Acrylic resin blocks were mounted to the inferior portion of a Universal Testing Machine (AGS-X series; Shimadzu Corporation., Kyoto, Japan). An adapted metal holder was fixed to the upper part of the testing machine that will grab the coronal part of the fiber post (Figure 3). The pullout test was performed at a crosshead speed of $1 \mathrm{~mm} / \mathrm{min}$, until the post were dislodged from the roots. The maximum force to dislodge each post was recorded by the system's software in Newtons (N). 


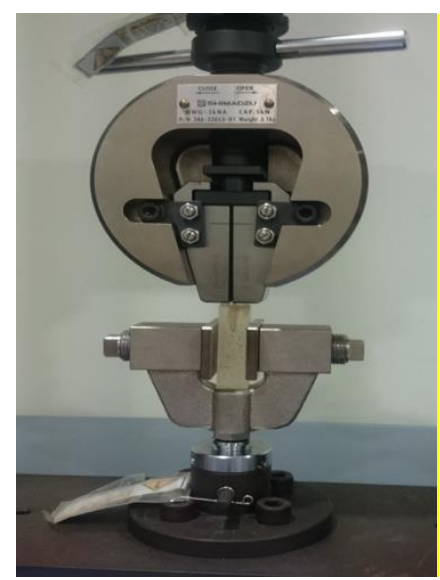

Fig 3. Universal Testing Machine. Adapted metal holder (upper part of the testing machine) grab the coronal part of the fiber post and resin block mounted at inferior portion

\subsection{Statistical analysis}

All data were analysed by using Statistical Package for the Social Sciences (SPSS) by IBM version 22. Independent t-test was subjected to statistical analysis to compare the mean differences of bond strength in two different barometric conditions (atmosphere and hyperbaric pressure). Statistical significance adopted was $\mathrm{p}<0.05$.

\section{Results}

The pull-out bond strengths and standard deviations (SDs) of two different barometric pressure conditions are shown in Table 1. The pull-out bond strengths of RelyXTM Unicem cement in atmospheric condition showed lower pull-out strength when compared with hyperbaric condition. Simple t-test analysis revealed that RelyXTM Unicem resin cement exhibited higher mean pull-out bond strength after exposure to hyperbaric pressure condition as compared when under normal atmospheric pressure condition $(\mathrm{p}>0.05)$.

Table 1 Mean Pull-out Bond Strength of Glass Fiber Post

\begin{tabular}{|l|c|}
\hline \multicolumn{1}{|c|}{ Barometric pressure } & $\begin{array}{c}\text { Mean pull-out bond strength (N) and stand- } \\
\text { ard deviation (SD) }\end{array}$ \\
\hline Atmospheric & $148.5( \pm 35.0)$ \\
\hline Hyperbaric & $245.8( \pm 46.3)$ \\
\hline
\end{tabular}

\section{Discussion}

In this in vitro study, the pull-out test represented a shear bond stress test that was used for determining the retention of glass fiber post in the root canal system. This test method gave a clear picture because it distributes the stress better and was able to accurately measure the bond strength between dentin and post compared to other tests like push-out and microtensile strength test [15]. 
Until recently, there has been very few studies in looking at the effect of bond strength of dental cements in different barometric pressure condition such as hyperbaric pressure condition. To the authors' knowledge, there have been very few papers published that have used a pressure chamber to create the hyperbaric pressure environment to test the bond strength of dental cements in hyperbaric pressure condition. Lyon et al. [14] which are the first in vitro study realisation of effect of hyperbaric pressure condition to the bond strength of dental cement. From in vitro study, they found that there was no significant reduction in bond strength for resin cement after pressure cycling [14].

However, the findings of the current study did not support the previous research. This study was unable to demonstrate that the bond strength of resin cement showed significant increase under hyperbaric pressure compared to bond strength in normal atmospheric pressure. A possible explanation for why the bond strength of RelyXTM Unicem resin cement was affected by the pressure cycling may be related to the concept of the cavity configuration factor (C-factor) formation inside the post canal space after cementation. $\mathrm{C}$-factor in root canals is defined as the ratio between the area of bonded resin cement to the root dentine free surfaces [16]. During the mixing and cementation process there must have been air trapped incorporated into mixture of the resin cement. Formation of air cavity inside the resin cement will increase the $\mathrm{C}$-factor and thus prevent the effective adhesion of the cement to the glass fiber post.

In hypebaric condition, when the environment pressure is higher than normal atmospheric pressure, the air trapped in the free surface between the post and the root dentin wall will contract resulting in volumetric contraction, or the presence of internal stresses. This can be explained by Boyle's law, which states that at a constant temperature, the volume of a gas varies inversely with the surrounding pressure [17]. However, because of the flexible properties of the resin cement [12], the $\mathrm{C}$-factor or free surface will decrease and more unattached area will be covered by the resin cement. Air trapped in luting cement may contract to adjust to the internal pressure to correspond to the high outer pressure. Furthermore, this condition may form the frictional retention that will enhance resistance to glass fiber post that cemented with RelyXTM Unicem cement.

According to Bouillaguet et al., the $\mathrm{C}$-factor in the post space are significantly higher when compared with intracoronal restoration. They reported that $\mathrm{C}$-factors in post spaces may exceed 200, compared to values between 1 and 5 in intracoronal restorations [18]. This factor may also explain the result of significant bond strength in hyperbaric pressure condition compared to normal atmospheric condition in present study. This contradicts with Lyon et al [14] previous study which stated there was no significant bond strength in hyperbaric pressure condition compared to normal atmospheric condition.

The clinical significance of present study should be tempered by its limitations. First and foremost, the present study mainly focuses on retention of glass fiber post with disrespect to the role of the core material and crown restoration in real clinical situation. Furthermore, other consideration regarding the limitation of in vitro study in anticipate the successful of technique and material in clinical use also should be 
noted. Hence, the need for further in vivo and in vitro studies with more realistic clinical conditions seems reasonable and more objective.

\section{Conclusion}

Within the limitations of this study, it can be concluded that: (1)The bond strength of glass fiber post cemented with resin had higher bond strengths in hyperbaric pressure condition than normal atmospheric pressure condition; (2) Using resin cement for glass fiber post cementation appear to be good strategy, for the patients such as divers, who are likely to be exposed to pressure cycling.

\section{Acknowledgements}

Authors would like to acknowledge supervisors, colleagues and staff of Faculty of Dentistry, UKM for their continuous support to make sure the success of this research

\section{References}

1. PADI [Internet]. Professional Association of Diving Instructors, Dive Theory - The Physics of Diving [cited March 2017]. Available online at https://www.idcguide.com/physics/

2. Zadik Y. Barodontalgia. J Endodont. 2009;35(4):481-5.

3. Zadik Y, Drucker S. Diving dentistry: a review of the dental implications of scuba diving. Australian dental journal. 2011;56(3):265-71.

4. Ranna V, Malmstrom H, Yunker M, Feng C, Gajendra S. Prevalence of dental problems in recreational SCUBA divers: a pilot survey. Br Dent j. 2016;221(9):577.

5. Robbins JW. Restoration of the endodontically treated tooth. Dent Clin North Am. 2002;46(2):367-84.

6. Sarkis-Onofre R, Pereira-Cenci T, Opdam NJ, Demarco FF. Preference for using posts to restore endodontically treated teeth: findings from a survey with dentists. Brazilian Oral Res. 2015;29(1):1-6.

7. Galhano GÁ, Valandro LF, De Melo RM, Scotti R, Bottino MA. Evaluation of the flexural strength of carbon fiber-, quartz fiber-, and glass fiber-based posts. J Endodont. 2005;31(3):209-11.

8. Goracci C, Ferrari M. Current perspectives on post systems: a literature review. Australian Dent J. 2011;56(s1):77-83.

9. Rosenstiel SF, Land MF, Crispin BJ. Dental luting agents: a review of the current literature. J Prosthet Dent. 1998 Sep 1;80(3):280-301.

10. Pereira JR, da Rosa RA, do Valle AL, Ghizoni JS, Só MV, Shiratori FK. The influence of different cements on the pull-out bond strength of fiber posts. J Prosthet Dent. 2014;112(1):59-63.

11. Bitter K, Meyer - Lueckel H, Priehn K, Kanjuparambil JP, Neumann K, Kielbassa AM. Effects of luting agent and thermocycling on bond strengths to root canal dentine. Int Endodont J. 2006;39(10):809-18.

12. Lia ZC, White SN. Mechanical properties of dental luting cements. J Prosthet Dent. 1999;81(5):597-609.

13. Gulve MN, Gulve ND. The effect of pressure changes during simulated diving on the pull out strength of glass fiber posts. Dent Res J. 2013;10(6):737.

14. Lyons KM, Rodda JC, Hood JA. Use of a pressure chamber to compare microleakage of three luting agents. Int J Prosthodont. 1997;10(5). 
15. Castellan CS, Santos-Filho PC, Soares PV, Soares CJ, Cardoso PE. Measuring bond strength between fiber post and root dentin: a comparison of different tests. J Adhes Dent. 2010;12(6):477-85.

16. Tay FR, Loushine RJ, Lambrechts P, Weller RN, Pashley DH. Geometric factors affecting dentin bonding in root canals: a theoretical modeling approach. J Endodont. 2005;31(8):584-9.

17. Musajo F, Passi P, Girardello GB, Rusca F. The influence of environmental pressure on retentiveness of prosthetic crowns: an experimental study. Quintessence Int. 1992;23(5).

18. Bouillaguet S, Troesch S, Wataha JC, Krejci I, Meyer JM, Pashley DH. Microtensile bond strength between adhesive cements and root canal dentin. Dent Mat. 2003;19(3):199-205. 